\title{
Rasgos fundamentales de la ética clásica de la virtud
}

\author{
JACOB BUGANZA TORIO \\ Universidad Veracruzana (México) \\ jbuganza@uv.mx
}

\begin{abstract}
Resumen
En este artículo, el autor expone algunos aspectos que considera fundamentales sobre la ética clásica de la virtud. Partiendo de algunos libros y artículos recientes, el autor destaca, primero, la gestación de esta ética en el marco de la antropología filosófica. Luego, expone la distinción clásica entre virtudes morales y dianoéticas para conceptuar con claridad el problema de la relación entre entendimiento y voluntad. Finalmente, expone en qué consiste la ५อóvnorৎ y la temperantia, así como la vinculación de las virtudes morales, el fenómeno moral y el bien moral.
\end{abstract}

Palabras clave: ética clásica, virtud, antropología filosófica y bien moral.

\section{Fundamental features of classical ethics of virtue}

\begin{abstract}
In this article, the author presents some fundamental aspects considered classical ethics of virtue. Based on some recent books and articles, the author emphasizes, first, the creation of this ethic in the context of philosophical anthropology. Then exposes the classic distinction between moral virtues and dianoetic to conceptualize clearly the problem of the relationship between intellect and will. Finally, it states what the yอóvnoss and temperantia and linking the moral virtues, moral phenomena and moral goodness.
\end{abstract}

Key words: classical ethics, virtue, philosophical anthropology and moral good.

Licenciado en Filosofía y Doctor en Estudios Humanísticos por el Tecnológico de Monterrey, Campus Ciudad de México. Profesor-investigador del Instituto y la Facultad de Filosofía de la Universidad Veracruzana. Coordinador de los posgrados en Filosofía en la misma universidad. Entre sus publicaciones destacan los libros Filosofía periodística. Un argumento para pensar (2007), Introducción esquemática a la historia de la filosofía (2008), El sery el bien (2010) y Panorama de los sistemas éticos de los siglos XIX y XX (2011). 


\section{Introducción}

La ética de la virtud encierra una dificultad que la diferencia de otras teorías generales que se han gestado al interior de la ética. Se trata de una dificultad histórico-temporal. ¿En qué sentido puede encerrar la ética de la virtud una dificultad de tal naturaleza? En que a diferencia de otras teorías generales que se han propuesto en el seno de la ética a lo largo de la historia, como la ética del deber en su versión deontológica, la ética utilitarista, la ética de la imparcialidad (que se relaciona ciertamente con la imparcialidad de la justicia), es que ha sido cultivada mucho más y por más tiempo que las enumeradas. A pesar de que pueden encontrarse puntos de referencia de las teorías éticas modernas en algunos escritores de otras épocas, la ética de la virtud incluye una cantidad impresionante de cultivadores que abarcan prácticamente toda la historia de la filosofía. Ciertamente la ética de la virtud tiene un decaimiento durante la filosofía moderna, pero es sólo aparente, pues numerosos autores, inspirados en la escolástica, la sostienen de una u otra manera, y en ciertos casos intentan complementar la ética de la virtud con las éticas modernas como sucede en algunas escuelas neoescolásticas que, partiendo del problema gnoseológico característico de la filosofía moderna, retoman aspectos tanto del kantismo como de la Escuela para complementarlos.

Ahora bien, y abonando a la tesis de la dificultad histórico-temporal antedicha, resulta cierto que cada cultivador de la ética de la virtud puede hacer más o menos general esta teoría, incluyendo en ella conceptos provenientes de otras corrientes y adaptándolas al concepto de virtud, de tal suerte que su tratamiento unitario resulta complicado. No existe una sola teoría de la virtud aceptada por todos los que desarrollan dicha versión de la investigación moral, más sí resulta cierto que tienen algunos puntos en común que pueden destacarse. Por ello mismo es que puede hablarse, como se desprende de la filosofía de MacIntyre, de una «tradición» de la ética «clásica» de la virtud. No es suficiente caracterizarla sin el adjetivo de "clásica», pues la virtud se ha entendido de distintas maneras en tradiciones rivales, como sucede, por ejemplo, con el concepto de virtù en Maquiavelo (Buganza, 2008) o como podría deducirse de la tradición genealogista inaugurada por Nietzsche (1972) ${ }^{1}$.

En un sentido etimológico, aquí hemos tomado como "pretexto» el loable libro de James Rachels que lleva por título en castellano Introducción a la filosofía moral. Su autor es uno de los más preclaros filósofos morales

\footnotetext{
$\mathrm{Al}$ respecto, las nociones maquiavela y nietzscheana de la virtud están más en consonancia con la tradición pre-socrática, en el sentido de que es Sócrates el primer filósofo moral reconocido como tal.
}

1 
recientes. En dicho libro, dedica un capítulo entero al estudio de la ética de la virtud. Su tratamiento, excelente en varias partes, en otras resulta deficiente, sin adolecer, por ello, de grandes defectos. Retomaremos algunos puntos de su exposición, pues nos da pie para presentar cinco de los rasgos más fundamentales de la ética clásica de la virtud. Se trata de aspectos que se reclaman unos a otros, lo cual explica por qué reiteradamente se vuelve sobre los pasos ya dados, pues los nuevos confirman los efectuados con anterioridad. Los rasgos a destacar son los siguientes: a) la ética en el marco de la antropología filosófica; b) virtudes morales y dianoéticas; c) la relación entendimiento-voluntad; d) la

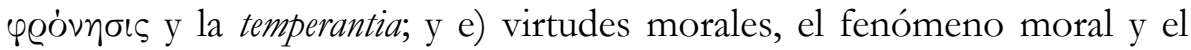
bien moral.

\section{1. Ética y antropología filosófica}

En primer lugar, nos parece incompleto el tratamiento que lleva a cabo Rachels acerca del marco conceptual en el cual se gesta la ética de la virtud. De acuerdo con él, una de las insuficiencias de la ética de la virtud consiste en lo siguiente:

Parece mejor ver a la teoría de la virtud como parte de una teoría global de la ética más que como una teoría completa en sí misma. La teoría total incluiría una explicación de todas las consideraciones que figuran en la toma de decisiones prácticas, junto con sus razones subyacentes. La cuestión, entonces, es si esa perspectiva total puede tener en cuenta tanto una concepción adecuada de la acción correcta como una concepción relacionada del carácter virtuoso de un modo que haga justicia a ambas [...] Nuestra teoría total podría empezar tomando el bienestar humano -0 para el caso, el bienestar de todas las criaturas que sienten- como el valor de suprema importancia. Podríamos decir que, desde un punto de vista moral, deberíamos querer una sociedad en que todos pudieran llevar vidas felices y satisfactorias (Rachels, 2007: 299).

Para comprender este argumento con mayor claridad, puede invertirse y simplificarse de la manera siguiente. Si la ética de la virtud pretendiera ser una teoría completa (lo cual no es nuestra intención demostrar aquí), requiere los siguientes dos elementos: (i) incluir una explicación de todas las consideraciones que figuran en la toma de decisiones prácticas junto con sus razones; y (ii) incluir un marco general que, hipotéticamente, la ética de la virtud no ofrece, como puede ser el bienestar o la felicidad (cosa que varias corrientes éticas ofrecen explícitamente, como sucede en el utilitarismo de Mill). 
(i) Resulta falso que la ética, en general, deba incluir una explicación de todas las consideraciones que figuran en la toma de decisiones prácticas. Si la ética tuviera como motivación explicar todas las consideraciones antedichas, las distinciones al interior de la filosofía práctica resultarían superfluas; incluso la ética incluiría una teoría sobre cuestiones prácticas que no implican la moralidad, como escoger entre beber un té de manzanilla o un té de tila, o entre escoger pintar un cuadro mediante el color verde o el rosa. Más bien, la ética tiene como cometido establecer directrices de acción en los actos que pueden denominarse propiamente morales, lo cual implica otro género de problemas. De aceptarse este primer criterio, parece difícil, por no decir imposible, que cualquier teoría ética lo satisfaga.

(ii) Resulta falso que la ética de la virtud no incluya el marco que pide Rachels. Por el contrario, al menos desde Aristóteles y Tomás de Aquino, el actuar moral no sólo no se motiva única y exclusivamente por el cumplimiento del deber (como parece desprenderse de la moral kantiana, aunque si se toma en general esta postura también ella apunta a la felicidad (Kant, 2002)), sino que considera de manera general la felicidad o el bienestar moral como motivos finales del acto moral. Hay otros peripatéticos antiguos, como Plutarco, que consideran que la

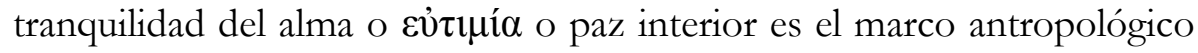
que señala la parte de exigencia moral que sólo de manera aparente no contiene la ética de la virtud. Sólo basta profundizar en alguna de sus variantes para caer en la cuenta de que sí posee un marco general, el cual es antropológico-ético ${ }^{2}$. Por ello no puede estarse de acuerdo con el filósofo estadounidense cuando asegura que la ética de la virtud está poco desarrollada, pues afirmar algo así requiere de un estudio más profundo que de facto no tiene intención de llevar a cabo Rachels (lo mismo sucede en otras partes de la obra, aunque no debe perderse de vista que se trata de una Introducción). Sin embargo, este error lleva a otros, entre los cuales destaca su discusión con Peter Geach. En efecto, al discutir el concepto de valentía (traducido en esta edición como «valor»), Rachels trae a colación el problema del soldado nazi. Aunque aparentemente sea valiente, si sus fines son inmorales, su valentía no es real. Rachels concluye que es valiente, y el valor es una cosa admirable; pero dado que pone su valor al servicio de una causa mala, su conducta es «en general» mala. Olvida Rachels, nos parece, que se trata de virtudes morales, y que éstas lo son si se encuentran al servicio del bien moral. No es que Geach y los teóricos de la ética de la virtud no consideren la

2 Por su parte, Dilthey (1956: 66) considera que la ética aristotélica se da en el marco de la metafísica y la psicología. 
valentía del soldado nazi, sino que no es valentía en sentido moral. El criterio de las virtudes morales tiene su asiento en el bien moral, rasgo que volverá a aparecer en el último apartado.

\section{Virtudes morales y dianoéticas}

En segundo lugar, por ningún lado en el trabajo de Rachels se aprecia la distinción más genérica de las virtudes. Se trata de un discernimiento que el propio Aristóteles (2000a y 2000b) elabora en la Ética nicomáquea. Rachels se refiere a las virtudes sin distinguirlas, lo cual puede ser grave en varios sentidos. $\mathrm{Al}$ menos uno resplandece con claridad, a saber, la definición de la virtud como término medio entre dos extremos, donde uno representa el exceso y otro el defecto. Es cierto que Rachels no se refiere directamente a esta definición, empero puede verse implicada al considerar que ésta se ve manifestada en una acción habitual, pues el concepto de acción, aunque no definido en el texto, tiene la carga del acto moral.

Veamos, por nuestra parte, esta importante distinción, aunque sea sucintamente. Ella parte de un principio antropológico, a saber, que son dos potencias distintas la facultad apetitiva y la facultad cognoscitiva, y que, además, las hay en distintos grados, a saber, inteligibles y sensibles. Esta distinción se prueba por los actos que cada una efectúa; si el hombre es capaz de conocer, entonces posee la facultad intelectiva; si el hombre es capaz de apetecer racionalmente, entonces posee la facultad apetitiva racional. Si esto es así, y siendo la virtud una perfección de la potencia, se sigue que la perfección de cada una de las facultades corresponde a virtudes distintas. Luego, hay virtudes dianoéticas o intelectuales y morales.

Aristóteles establece en la Ética nicomáquea que en el hombre hay una parte del alma que es irracional, otra racional por participación y una más que es racional por completo. Para lograr distinguir estas partes del alma, Aristóteles afirma primero que una parte es racional ( $\lambda$ ó $\gamma o v)$ y otra

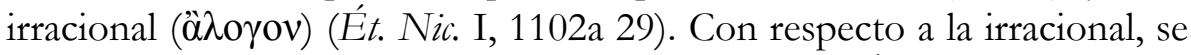

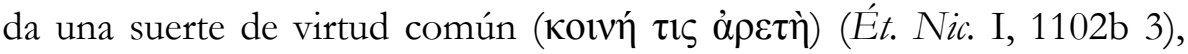
pues se refiere a la perfección con la cual se efectúan los procesos irracionales, como es la nutrición. Hay otra parte del alma que, aunque irracional, «participa ciertamente de algún modo de la razón» ( $\mu \varepsilon \tau \varepsilon \dot{\chi} \chi \sigma v \sigma \alpha$

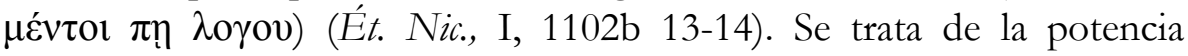
apetitiva, que puede someterse o no a lo que la razón le indica. Se trata de una suerte de potencias apetitivas que no siempre siguen a la razón, 
por lo cual es posible perfeccionarlas sólo en cuanto participan de la racionalidad. La causa es fácil de descubrir: lo que es irracional no es susceptible de ser comandado o estar bajo el imperio de la razón. Siendo así, lo que participa parcialmente de la razón puede ser parcialmente comandado y, por tanto, perfeccionado racionalmente. De ahí que no sea el apetito sensible el que directamente se perfecciona a través de la virtud, sino en cuanto él participa de la parte racional. El hábito que se denomina virtud moral es la que dispone a la facultad apetitiva, pues de esta suerte es capaz de participar la parte racional de la parte irracional. Por ello, Aristóteles distingue la virtud en dianoéticas y éticas $(\lambda \varepsilon \dot{\varepsilon} \gamma \mathrm{\mu} \mu \varepsilon v$

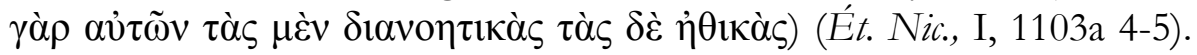

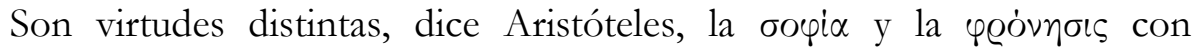
respecto a $\sigma \omega \varphi \varrho o \sigma u ́ v \eta ;$ las primeras son dianoéticas, mientras que la última es ética.

Quien esquematiza de mejor suerte esta concepción sobre la virtud es Tomás de Aquino (1967). Ciertamente parte de la tesis que asegura que la virtud sólo puede residir en la parte racional del alma, pero en cuanto la parte irracional tiene vinculación política con la racional, es sujeto de virtud. De ahí que escriba:

Irascibilis et concupiscibilis dupliciter considerari possunt. Uno modo secundum se, inquantum sunt partes appetitus sensitivi. Et hoc modo, non competit eis quod sint subiectum virtutis. Alio modo possunt considerari inquantum participant rationem, per hoc quod natae sunt rationi obedire. Et sic irascibilis vel concupiscibilis potest esse subiectum virtutis bumanae: sic enim est principium humani actus, inquantum participam rationem. Et in his potentiis necesse est ponere virtutes (Suma Teológica, III, q.56, a.4c).

Para dar cuenta de esta tesis, Aquino recurre al símil del artífice y su instrumento. Para que la obra del artífice sea adecuada, es necesario que tanto él como su instrumento estén bien dispuestos a obrar. De la misma manera, la razón y el apetito sensible se disponen a obrar de acuerdo con la virtud; pero es el apetito sensible, finalmente, el que actúa en conformidad con la razón para ser virtuosa. A su vez, esta postura depende de la tesis tomista que asegura que una virtud puede estar en dos o más sujetos (entendiendo en este sentido por sujeto el equivalente a potencia). Puede estar, pero en distinto grado, esto es, según cierto orden (sed ordine); así, «una virtus pertinere potest ad plures potentias; ita quod in una sit principaliter, et se extendat ad alias per modum diffusionis, vel per modum dispositionis; secundum quod una potentia movetur ab alia, et secundum quod una potentia accipit ab alia» (S.T., I-II, q.56, a.2c). En este caso, la parte 
irracional recibe algo de otra (accipit ab alia), a saber, recibe la virtud de la razón.

Pero este planteamiento implica una aporía importante, que sólo se despeja si se tienen muy en cuenta los términos que se hallan en la discusión. La aporía consiste en la racionalidad de la voluntad. Pero, si se tienen en cuenta las palabras del Aquinate, el problema parece aclararse. Cuando Santo Tomás se refiere a estos asuntos, tiene particular atención al escribir appetititus virtus (facultad apetitiva), y no propiamente voluntas. Tal parece que lo que tiene en mente el filósofo medieval es un término que englobe tanto al apetito sensible como al inteligible. Sin duda el apetito sensible se encuentra implicado en las virtudes morales, como queda de manifiesto al haber considerado este apetito en su bifurcación concupiscible e irascible; pero, ¿se refiere también Tomás de Aquino a la voluntad? ¿Está implicada la voluntad en el appetititus virtus? La respuesta parece ser afirmativa. Escribe en la segunda objeción de la cuestión cincuenta y ocho de la prima secundae que toda virtud puede hacerse por elección, pero sólo la parte apetitiva del alma puede elegir rectamente, pues elegir es acto de una parte (anímica) apetitiva (eligere est actus appetitivae partis; S.T., I-II, q.58, a.1, ad.2). Pero lo propio de la libre voluntad es elegir; luego, también la voluntad está implicada en la facultad apetitiva. De ahí que sea ella la que se perfeccione moralmente, como se verá más adelante. Pero antes de seguir por otro rumbo, que conecta precisamente con esto último, vale la pena retener las palabras de Gómez Robledo (2001: 333-334), pues echan luz importante sobre este asunto:

Las virtudes intelectuales son, por decirlo así, iluminativas de la razón, contribuyendo cada cual en su esfera a vivificar la claridad de la razón en su función teórica o práctica, al paso que la voluntad es, como lo enseña uniformemente la escuela peripatética, una potencia ciega en el sentido de que no percibe por sí misma, sino que ha de dirigirse a lo que otras potencias perceptivas le propongan como objeto de la acción. Hay en ella apenas una determinación constante en cuanto que necesariamente tiende al bien y no puede obrar sino sub ratione boni, pero unas veces se decidirá por el bonum intelligibile que le muestra la razón y otras por el bonum sensibile que le propone al apetito inferior la percepción sensible, y en esta opción está sencillamente toda la vida moral, meritoria o vituperable, del hombre.

Queda claro que la voluntad o bien sigue lo que le muestra la razón, a través de la cual puede perfeccionarse moralmente, o bien se encamina al bien que le proporciona el conocimiento sensible y, en consecuencia, el apetito inferior. Seguir el sendero de la razón es, para el filósofo 
mexicano, sumamente meritorio, aunque no tiene por qué no ser igualmente valioso seguir el apetito sensible. Lo cierto es que esta especulación se vincula estrechamente con el tema de la relación entre el entendimiento y la voluntad, que brevemente revisaremos a continuación.

\section{La relación entendimiento-voluntad}

Tampoco se ve en el texto de Rachels el árido problema de la relación que hay entre el entendimiento y la voluntad. Esta carencia se debe precisamente a lo antedicho: no distingue entre virtudes intelectuales y morales. Empero, la relación entrambas facultades es un problema fundamental, que Nicolai Hartmann (1961: 163) de manera lacónica caracteriza así: «El hombre ve, sin duda, a menudo el bien, pero por flaqueza no es capaz de hacerlo». Quien también caracteriza el problema es MacIntyre. Él parte del problema gnoseológico para alcanzar las dificultades antropológicas y éticas que contiene la síntesis tomista entre agustinismo y aristotelismo. El escocés afirma:

Tomás de Aquino utiliza la explicación platónica propuesta por Agustín para caracterizar una serie de relaciones - las de los particulares con los ejemplares en la mente divina creadora que son sus causas formales- y la explicación de Aristóteles para caracterizar otra serie de relaciones, las que están entrañadas en la aprehensión por parte de la mente de la quidditas rei materialis, que es el objetivo inicial del conocimiento e investigación de la mente. Donde la psicología de Aristóteles excluía la posibilidad de dar cuenta del fenómeno de la voluntad, al tiempo que Agustín carecía de lo que Aristóteles proporcionaba con sus descubrimientos sobre las potencias de la mente y sus encarnaciones teóricas y prácticas en la investigación, el Aquinate pudo mostrar cómo la voluntad, concebida a la manera agustiniana, podía tanto estar al servicio de la mente, como también, no obstante, engañarla, entendida la mente a la manera de Aristóteles (MacIntyre, 1992: 163).

La voluntad resulta decisiva para la ética clásica de la virtud, pues es la que se perfecciona desde el punto de vista de las virtudes morales. En otros términos, no es el entendimiento el que se perfecciona moralmente, sino la voluntad. Es la voluntad iluminada por el entendimiento la que tiene la fuerza para encausar las pasiones, para motivar la fortaleza y la templanza en el agente moral. Además, la voluntad tiene la fuerza para deformar el conocimiento intelectual; es 
capaz de desvirtuar el bien que concibe el entendimiento para buscar otro bien que puede ser menor jerárquicamente al primero.

Cabe entresacar otras consecuencias que se derivan de la carencia del texto de Rachels con respecto a la relación mutua entre el entendimiento y la voluntad. Esta laguna también se encuentra en la postura de Hernández Castro, en quien el bien moral está ausente. En efecto, la adecuación o no desde el punto de vista de lo honesto con respecto a lo que conoce el entendimiento, es asunto de la voluntad (Rosmini, 2010). Por eso para el peripatético Francesco M. Zanotti la voluntad es la que propiamente puede ser virtuosa o viciosa: «El sujeto de la virtud es el virtuoso en cuanto quiere; o es la voluntad misma del virtuoso» (Il soggetto della virtù è il virtuoso, inquanto egli vuole; ovvero è la volontà stessa del virtuoso). Esgrime el boloñés lo siguiente a favor de la tesis: «Il soggetto d'un abito è aquella potenza, che fa gli atti, per cui s'acquista tale abito; ma la virtù è un abito; $e$ la volontà è quella potenza, che fa gli atti virtuosi, per cui s'acquista un tale abito; dunque la volontà è il soggetto della virtù» (Zanotti, 1784: 7) ${ }^{3}$.

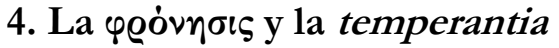

Rachels tampoco muestra dos virtudes fundamentales para el ámbito moral, a saber, la prudencia y la temperancia. Se enfoca en tratar algunas de las particularidades que adquieren, aunque sin mencionarlas. Se dedica expresamente al valor (la valentía), la generosidad, la sinceridad y la lealtad a la familia y amigos. Ciertamente se echa de menos el tratamiento de aquellas dos virtudes, las cuales revisten una importancia mayúscula en la ética clásica de la virtud.

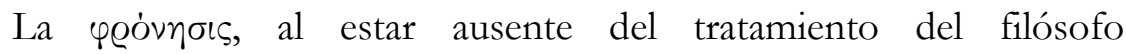
estadounidense, deja mutilada la comprensión que debe obtenerse de la

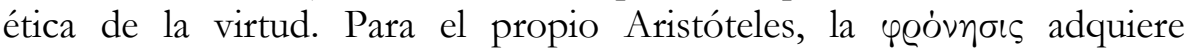

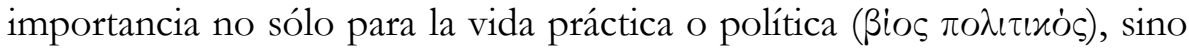

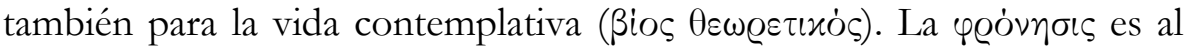
mayordomo lo que la бọia es al señor de la casa. Para tener clara la analogía, hay que decir que así como el señor se relaciona con el mayordomo y este último con los subordinados, de la misma manera la

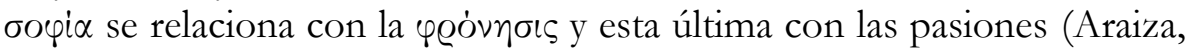
2007). Y es precisamente en el dominio y encausamiento de estas últimas

3 Nuestra traducción: «El sujeto de un hábito es aquella potencia que hace los actos, por los cuales se adquiere tal hábito. Pero la virtud es un hábito. Y la voluntad es aquella potencia que hace a los actos virtuosos, por la cual se adquiere un tal hábito. Por tanto, la voluntad es el sujeto de la virtud». 
donde tienen lugar las distintas virtudes éticas. Por ello, dejar de

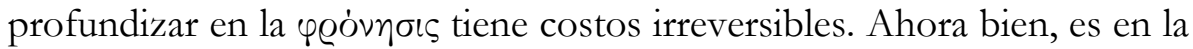
vida política donde se realizan las distintas virtudes, cuya rectora es la

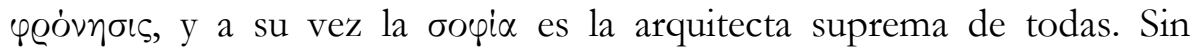
embargo, no son equivalentes, pues puede darse la sabiduría sin la prudencia y esta última sin la primera. De ahí que sean distintas.

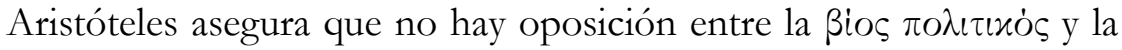
ßios $\theta \varepsilon \omega \varrho \varepsilon \tau \iota x$ s. Es posible vivir una vida conforme con ambas, lo cual equivale a decir que es posible vivir una vida que se rija de acuerdo con las dos virtudes características en ambas especies de vida. Es más, algunos pasajes de la obra aristotélica sugieren que es necesario, antes de alcanzar las ciencias teoréticas, que son consideradas el fin de todo el movimiento, gobernar la parte irracional del alma, esto es, las pasiones. Y la manera de lograr esto último y preparar al alma para la contemplación

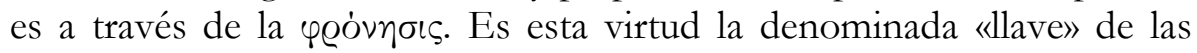
otras virtudes, pues estas últimas, si se mantiene la metáfora del señor, son las que encausan a las pasiones. Es la y@óvnoıs la administradora general, y a ella responden las otras virtudes. De ahí el papel mayúsculo que tiene no sólo para la ética de la virtud aristotélica, sino para toda ética clásica de la virtud.

Desde el punto de vista de Alasdair MacIntyre, las virtudes y las normas están interrelacionadas, pues ser virtuoso o poseer la virtud implica que el agente sabe aplicar la normatividad a los casos específicos. Por ejemplo, poseer la virtud de la justicia implica tanto la voluntad de dar a cada quien lo que le es debido como el conocimiento de cómo aplicar las normas (generales) a casos cada vez más concretos que impidan la violación del orden (justicia). El escocés asienta: «Entender la aplicación de las normas como parte del ejercicio de las virtudes es entender la cuestión del seguimiento de las normas, precisamente porque no se puede entender el ejercicio de las virtudes a no ser en función del papel que tienen en la constitución del único tipo de vida en el cual ha de lograrse el telos humano» (MacIntyre, 1992: 180). Esta aplicación de las normas se relaciona con la prudencia, la cual es la virtud que capacita al agente para aplicar lo universal a lo particular, es decir, es la virtud que permite actuar de manera que el universal se aplique en lo particular. Ahora bien, precisamente la referencia previa al texto de MacIntyre pone al descubierto una crítica que se efectúa frecuentemente contra la ética de la virtud: la presuposición de que sólo hay un «telos humano». Tal vez una suerte de respuesta vaya en la siguiente dirección: la normatividad, las virtudes, las pasiones y las acciones son partes de un único todo (cfr. MacIntyre, 1992: 180). Es imposible brindar todas las características accidentales de un ente, lo cual se aplica igualmente al caso del agente 
moral. Pero en general, puede decirse que es un ente material, biológico, social y espiritual. Son estos aspectos generales los que han de integrarse armónicamente con la finalidad de que el agente pueda alcanzar su perfección, que en este caso es su perfección como ser humano, pues la perfección humana equivale a la perfección moral (Buganza, 2011: 335360).

El ser humano es un ente con múltiples facetas que es capaz de desarrollarse en distintas direcciones. Se espera, desde la ética clásica de la virtud, que tales capacidades se desenvuelvan armónicamente con el bien moral, pues lo que cualifica al hombre en cuanto tal es dicho bien y no los bienes restringidos. Ciertamente estos últimos son imprescindibles, pero es el bien moral aquel que cualifica al hombre qua ser humano. Se trata de un bien que, aunque recae en el individuo, no se da independientemente o al margen de la comunidad. El bien moral recae en el individuo situado en el plexus de la comunidad. Tal vez en esto último pueda encontrarse un punto de confluencia con la tesis de Daniel Hernández Castro, para quien la virtud clásica se vincula con la democracia radical. En su trabajo El compromiso de Eneas, Hernández Castro (2009: 137-162) sostiene que para esquivar la aporía de la virtud (expuesta en los términos de José Luis Calvo y William K. C. Guthrie), a saber, que la virtud moral se define recurriendo al justo medio y que este último se define recurriendo a la virtud, ha de proponerse que la virtud moral no sólo es un medio, sino un fin que se efectúa en su propio acto ${ }^{4}$.

En el contexto de la aporía mencionada, Hernández Castro (2009: 148) mantiene constantemente un diálogo y crítica con MacIntyre, pues considera que el escocés sostiene una idea «metafísica» del bien a la usanza platónica (llega a denominar a la postura de MacIntyre como «ahistórica», a pesar de que el escocés reiteradamente se refiere a la tradición). Aunque su crítica no resulta del todo contundente, pues no se aprecia bien una postura de tal cuño en MacIntyre a partir de los textos que recoge para llevar a cabo su juicio, sí parece importante retomar la

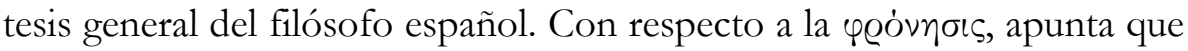
ésta posee una doble perspectiva:

\footnotetext{
4 Este autor, luego de citar la aporía en Guthrie, escribe lo siguiente: «Por un lado, las actividades de la virtud se ocupan de la deliberación y la elección, que son los medios para alcanzar el fin, que es objeto del deseo; por otro, es la virtud quien hace que sea recto el objetivo, o sea, quien se ocupa del fin, mientras que la Prudencia sería la encargada de realizar los medios para conseguirlo» (Hernández Castro, 2009: 146). Tal vez una salida a este escollo sea sostener, como lo hace Araiza, la distinción entre virtudes morales y dianoéticas. Siendo la sabiduría una virtud, se comprende que la virtud puede estar referida al fin y a los medios, pues la primera es objeto de la $\sigma o \varphi i \alpha$, mientras que la

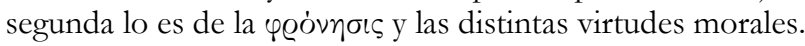


Por un lado, sería la facultad práctica que decide sobre las circunstancias particulares variables y es capaz de captar las situaciones relevantes y decidir sobre ellas de la forma correcta [...] En este aspecto, la Phrónesis se ocuparía de los medios. Pero hay una segunda dimensión, obviada por la crítica moderna, que alude a la clase de excelencia que la Phrónesis realiza en sí misma, es decir, no con el tipo de finalidad práctica que supone ocuparse de los medios, sino con el tipo de actividad (energeia) que supone ya la plena realización del fin (Hernández Castro, 2009: 157).

Pero, ¿cómo es que puede sostenerse esta excelencia de la virtud? Más concretamente: ¿por qué la virtud moral es excelente? Tal vez una suerte de respuesta es que la virtud moral posee tal excelencia debido a que perfecciona al hombre en aquella dimensión que sólo él posee y que resulta universalizable, a saber, la moralidad. Es lo que Hernández Castro no puede aceptar, pues es análogo a lo que él llama «metafísico» (lo cual, aunque sin justificación, parece desechar). De ahí que su postura no logra aterrizar y, por tanto, carezca del elemento que busca precisamente el acto virtuoso, a saber, el bien moral, que es el bien propio del hombre

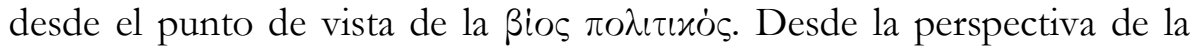

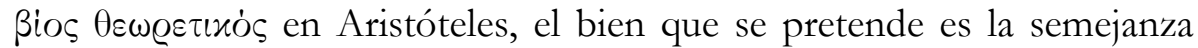
con la divinidad, que es la contemplación. Pero estas dos $\beta i \alpha$ no son contradictorias, sino que pueden complementarse. Desde la perspectiva del aristotelismo, esto es posible porque el hombre es tanto social como teórico. En efecto, no es otra la razón por la cual Aristóteles habla tanto de la бoyia como de la yeóvnoıs en el mismo espacio al asentar lo siguiente:

Digamos que estos modos de ser han de ser necesariamente elegibles por sí mismos, al menos por ser cada uno de ellos la virtud de la correspondiente parte del alma, aun en el caso de no producir nada ninguno de ellos. Mas, de hecho, producen algo, no como la medicina produce la salud, sino como la produce la salud misma; es de esta manera como la sabiduría produce felicidad. Pues, siendo una parte de la virtud total, produce felicidad con su posesión y ejercicio. Además, la obra del hombre se lleva a cabo por la prudencia y la virtud moral, porque la virtud hace rectos el fin propuesto, y la prudencia los medios para este fin (Ét. Nic., VI, 12, 1144a $1-10)$.

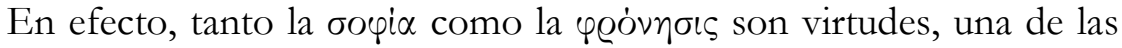
cuales perfecciona la parte dianoética del alma, mientras la otra realiza lo

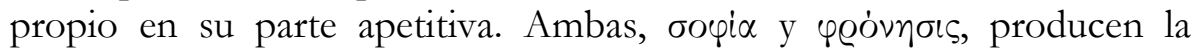
felicidad, y por ello también están hermanadas. En consecuencia pueden darse en la misma vida, es decir, la vida humana puede ser tanto política 
como teórica, pues no hay razón concluyente para afirmar las virtudes de ambas como enemigas. Simplemente sucede que la virtud de la бoyi $\alpha$ se da en el estudio, mientras que la virtud moral se da en el seno de la

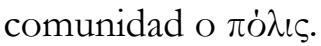

En este mismo sentido, el virtuoso tiene las siguientes tres propiedades. La primera es que el virtuosismo es algo adquirido, pues ninguno es virtuoso por naturaleza. Esta propiedad es evidente en cuanto que el hábito se define como algo que sobreviene mediante el uso que perfecciona al agente moral en cuanto tal, lo cual implica esfuerzo y perseverancia. La segunda propiedad es que quien actúa virtuosamente lo hace con placer. El silogismo de Zanotti (1784: 7) es claro y contundente: «Il virtuoso vuole l'azion virtuosa, e la fa; ora niuno può far quello, che vuole, senza sentirne piacere; dunque il virtuoso fa l'azion virtuosa con piacere»". En tercer lugar, el virtuoso efectúa la acción virtuosa virtuosamente. Esto quiere decir que quien realiza la acción virtuosa lo hace porque quiere ser virtuoso y no por algo más, como acontece por ejemplo con la virtù maquiavélica. Ciertamente es difícil enjuiciar si el agente realiza la acción por virtud o por aparentarla simplemente. Lo que en la ética clásica se denomina intentio del agente es algo que sólo puede saber a ciencia cierta el agente en cuestión. Para el observador externo el asunto permanece sólo en la apariencia y sólo así puede juzgar el acto virtuoso o no en cuanto es hecho virtuosamente. Tal vez aquí tenga mucho que ver lo que Scheler afirma con respecto al querer y al actuar, que no debe ser, dicho sea de paso, un actuar aislado, sino que sugiere sea constante: «El que no quiere hacer bien a su prójimo - de manera que le interese la realización de ese bien- y toma sólo la ocasión 'para ser bueno' o 'hacer el bien' en ese acto, no es bueno ni hace verdaderamente el 'bien', sino que en realidad es una especie de fariseo que quiere solamente aparecer 'bueno' ante sí mismo». Y por eso asienta que «El bien más puro e inmediato, e igualmente el mal más puro también, están dados en el acto del querer que de un modo enteramente inmediato sin una 'elección' precedente se ajusta a la preferencia» (Scheler, 2001: 74-75).

Por su parte, la templanza es igualmente una virtud, pues lo propio de la virtud, como dice el Aquinate, es inclinar al hombre al bien a través de la razón; y la templanza, como su mismo nombre lo señala, es la moderatio o temperies que establece la propia razón. Ahora bien, la temperantia significa cierto equilibrio en las obras que efectúa el hombre, así como en sus pasiones, especialmente retrayendo (retrabit) al agente de

5 Nuestra traducción: «El virtuoso quiere la acción virtuosa, y la hace; ninguno puede hacer aquello que quiere sin sentir placer; luego, el virtuoso hace la acción virtuosa con placer». 
aquellos objetos que llaman al apetito en contra del recto orden de la razón, a la cual han de subordinarse. De hecho, esta es precisamente la causa por la cual existen las virtudes morales. A diferencia de la fortaleza, que se enfoca al mal sensible o corporal (ad fugam corporalium malum), la templanza es una virtud que se enfoca al bien sensible, esto es, a los deseos y placeres (circa concupiscentiam et delectationem), especialmente a los táctiles (S.T., II-II, q. 141, aa. 1-5). Siendo tales apetitos necesarios para la vida humana, así como para la vida animal en general, pues implican el alimento y la reproducción, resulta que se trata de una virtus cardinalis. La moderación está presente en toda virtud, especialmente estos apetitos necesarios al hombre, como lo escribe Tomás de Aquino:

Moderatio autem, quae in omni virtute requiritur, praecipue laudabilis est in delectationibus tactus, circa quae est temperantia: tum quia tales delectationes sunt magis nobis naturales, et ideo difficilius est ab eis abstinere et concupiscentias earum refrenare; tum etiam quia earum obiecta magis sunt necessaria praesenti vitae, ut ex dictis patet (a. 4.5). Et ideo temperantia ponitur virtus principalis seu cardinalis (S.T., II-II, q. 141, a. $7 \mathrm{c})$.

Como se puede apreciar en este apartado, tanto la prudentia como la temperantia resultan cruciales para comprender la ética clásica de la virtud. Sin ellas, que son virtudes principales, esta ética aparece desdibujada. Y es que la temperantia trata precisamente con lo más próximo a la naturaleza humana, a saber, con los apetitos sensibles que se refieren al bien «juzgado» así por la sensibilidad. Se trata de acontecimientos con los cuales el hombre trata día a día, y que sin la intervención de la templanza como virtud cardinal sería difícil sortear moderadamente el acontecer diario.

\section{Virtudes morales, el fenómeno moral y el bien moral}

Rachels asegura, de manera concisa, lacónica y exacta, que la virtud (moral) es la virtud de la persona como tal. Por ello, define la virtud como «un rasgo de carácter manifestado en una acción babitual, que es bueno que una persona tenga» (Rachels, 2007: 277-278). En efecto, el concepto clásico de virtud implica al de hábito, el cual consiste en una repetición de actos. Por ello, el concepto de hábito, de manera originaria, hace referencia a las potencias humanas, las cuales son capaces de actualizarse en distintas direcciones y, una vez repetidas y en cierto modo instaladas, se vuelven hábitos. Algunos de estos hábitos, casi sobra decirlo, se relacionan con el actuar que vuelve bueno al hombre como tal, es decir, con la moralidad. 
En este contexto, las virtudes y vicios son hábitos relacionados con la moralidad. Por ello son importantes no sólo para la ética, la cual los estudia, sino para la vida cotidiana. Frente a la cuestión de por qué son importantes las virtudes, Rachels expone su argumento de manera muy convincente y clara. La persona virtuosa alcanza una vida buena, que es una vida buena moralmente. De ahí que Rachels escriba que «Las virtudes son importantes porque a la persona virtuosa le va mejor en la vida $[\ldots]$ Las virtudes se necesitan para guiar bien nuestras vidas» (Rachels, 2007: 287). Son importantes porque, con ellas, puede lograrse una buena vida y, por tanto, perfeccionarse en cuanto ser humano, es decir, moralmente.

En este contexto, Rachels destaca con tino la universalidad de la virtud. No puede ser sino una consecuencia de lo antedicho. En efecto, si el ser humano tiene potencialidades que lo hacen disponerse a actuar de manera correcta desde el punto de vista de la moralidad, y si estas disposiciones son las que cualifican al hombre para lograr una vida buena moralmente, entonces todo ser humano está dispuesto a lograr la buena vida moral adquiriendo dichas disposiciones llamadas virtudes. Rachels se pregunta y responde en dónde radica la universalidad de la virtud, especialmente frente a la multiplicidad normativa establecida por las sociedades de todos los tiempos. Básicamente la respuesta se halla en el silogismo anterior, a saber, en la universalidad de la condición humana; debido a que hay igualdad esencial entre los hombres, y el bien del hombre ha de ser el bien del hombre en cuanto tal, entonces tal bien es el moral, pues es aquello en lo cual todo hombre puede perfeccionarse. Rachels elabora su argumento en estos términos:

Puede ser cierto que en sociedades distintas se les da a las virtudes interpretaciones diferentes, y diversos tipos de acciones cuentan como satisfactorios, y puede ser cierto que como algunas personas llevan tipos particulares de vidas en tipos particulares de circunstancias, tienen necesidad de algunas virtudes más que otros. Pero no basta simplemente decir que si cualquier rasgo de carácter particular es una virtud sólo es cuestión de convención social. Las virtudes más importantes no son mandatos de convenciones sociales, sino de hechos básicos acerca de nuestra condición común (Rachels, 2007: 290).

El virtuoso, a nuestro juicio, se perfecciona como agente moral, que es lo mismo que decir que se perfecciona como persona, o sea, qua hombre. Para argumentarlo mejor puede afirmarse lo siguiente: el bien exclusivo del hombre es el bien moral; el bien moral se actualiza mediante la virtud; luego el bien exclusivo del hombre consiste en la 
virtud. Pero el bien exclusivo del hombre es su perfección; en consecuencia, el hombre se perfecciona en cuanto hombre mediante la virtud.

MacIntyre logra visualizar en Dependent Rational Animals la importancia del bien moral, pues distingue al menos tres tipos de bondad (goodness). Discierne, primero, los bienes que se evalúan así en cuanto son medios, como poseer ciertas habilidades, estar en ciertos lugares en momentos idóneos, etcétera, pero "These things are good only qua means to something further that is itself good». En segundo lugar, distingue lo que él ha venido llamando, desde After Virtue, como «internal goods», a saber, los bienes que se obtienen a través de ciertas prácticas implicadas en una práctica social establecida: «To be excellent in achieving the goods of this or that particular practice is to be good qua member of a fishing crew or qua mother of a family or qua chess player or soccer players. Pero hay también otro tipo de bien, de acuerdo con MacIntyre (por ello se inscribe en la mejor tradición de la ética clásica de la virtud). Se trata, en síntesis, del bien que perfecciona al hombre qua hombre. Esta distinción es consecuencia de su razonamiento: "We therefore need to distinguish between what it is that makes certain goods goods and goods to be valued for their own sake from what it is that makes it good for this particular individual or this particular society in this particular situation to make them objects of her or his or their effective practical regard》 (MacIntyre, 2001: 66-67). Esta «visión práctica efectiva» resulta fundamental, pues el hombre no sólo se perfecciona o desarrolla a través de ciertos bienes restringidos, sino que también se desarrolla $o$ perfecciona en cuanto hombre.

El bien moral es el bien que caracteriza precisamente a la virtud moral. De no aceptarse dicho bien, las virtudes se desdibujan hasta caracterizarse como ciertas «habilidades» para obtener otros bienes más fundamentales. Ya no serían, en consecuencia, necesarias para lograr el

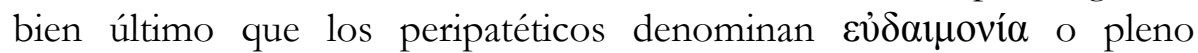
desarrollo humano («human flourishing», lo llamaría MacIntyre). Al faltar el bien moral, se carece del sustento ontológico para proponer la importancia y necesidad de la virtud para el hombre. De ahí que sea deficiente una exposición de la ética clásica de la virtud, al menos en su vertiente más aristotélica-tomista, que obvie la envergadura del bien moral en la vida práctica del hombre. 


\section{Conclusiones}

Aún cuando la exposición de James Rachels sobre la ética de la virtud sea loable en muchos sentidos, algunas ausencias vuelven deficiente su presentación. En este trabajo hemos destacado tanto una parte como la otra, intentando en todo momento una comprensión más cabal de la ética clásica de la virtud. Por ello, la pretensión del texto ha sido la de completar, con el pensamiento de otros filósofos, entre los que descuellan Aristóteles, Tomás de Aquino y MacIntyre, la visión de esta postura filosófica que, por más que tenga varias versiones y haya surcado prácticamente la totalidad de la historia de la filosofía, sigue cultivándose y actualizándose con provecho.

Por lo anterior puede sostenerse que la ética clásica de la virtud no es una posición que haya dejado de tener vigencia. Es más, esta ética, al buscar fundamentos ontológicos para sostener sus propuestas, pretende, en el mejor sentido del término, ser filosofía, es decir, no mera sociología moral, aunque sea a partir de ella que la ética se construye. En definitiva, busca construir una posición filosófica, esto es, ontológica, de lo que es y debe ser el hombre.

Pero esta ontología tiene muy claro que la moral es indispensable. Le es diáfano porque el razonamiento práctico implica a la $\pi \dot{\lambda} \iota \iota$, pues la moral, aunque en alguna acepción sea también individual, es primordialmente social o común. En la ética clásica de la virtud no se trata solo de individuos aislados que buscan su desarrollo o perfeccionamiento a través de los actos morales, sino de individuos insertados en el plexus de la $\pi \dot{\lambda} \iota \varsigma$, , con distintas relaciones sociales (implicadas por supuesto las de poder) y en busca de un bien que no sea únicamente individual, sino precisamente un bien común. Y es que ontológicamente el hombre no sólo es una entidad que se desarrolla individualmente, sino que es, en este sentido, un ente en relación con los otros, un ente en relación con su comunidad. De ahí que el desarrollo individual no sea independiente del desarrollo de la comunidad.

No parece ser otra la conclusión a la que llega MacIntyre al escribir lo siguiente: «Since for a buman being to flourish unqualifiedly qua human being, it is her or his life as a whole that must flourish, the individual has to learn through experience about the places both of independence and of dependence on others in the different stages of a flourishing life» (2001: 113). Debido a que el hombre es parcialmente independiente (en su razonamiento práctico, por ejemplo) y parcialmente dependiente, es necesario que sepa, en vistas a su desarrollo o perfeccionamiento total, distinguir las virtudes que debe cultivar en cada instante, en cada situación determinada. $\mathrm{Y}$ es precisamente la 


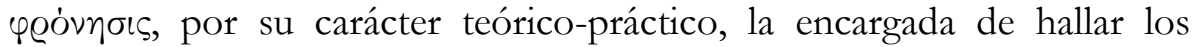
medios convenientes para dirigir al agente hacia su perfeccionamiento.

\section{REFERENCIAS}

-Aquino, T. (1967). Suma Teológica. Madrid: Biblioteca de Autores Cristianos.

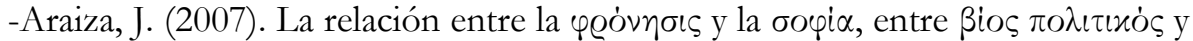

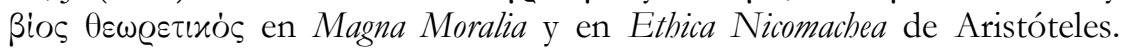
Nova Tellus, 25 (2), 181-207.

-Aristóteles (2000a). Ética nicomáquea (J. Pallí Bonet, Trad.). Madrid: Gredos. -Aristóteles (2000b). Etica Nicomachea (Versión griega). Milano: Bompiani. -Buganza, J. (2008). Ser y aparentar en Maquiavelo. Iustitia (18), 135-152.

-Buganza, J. (2011). La analogicidad del bien y su relación con el valor moral. En L. Álvarez (Ed.), La hermenéutica en el cambio de siglo. Entre el rescate de la tradición y el reto de la creatividad (págs. 335-360). México: Ducere.

-Dilthey, W. (1956). Historia de la filosofía (E. Ímaz, Trad.) (Segunda edición). México: Fondo de Cultura Económica.

-Gómez Robledo, A. (2001). Ensayo sobre las virtudes intelectuales. En A. Gómez Robledo, Obras (T. III, págs. 309-548). México: El Colegio de México.

-Hartmann, N. (1961). Introducción a la filosofía (J. Gaos, Trad.). México: UNAM.

-Hernández Castro, D. (2009). El compromiso de Eneas. Virtud y democracia radical tras la dialéctica de la Ilustración. Isegoría. Revista de Filosofía Moral y Política (41), 137-162.

-Kant, I. (2002). Teoría y praxis. Buenos Aires: Leviatán.

-MacIntyre, A. (1992). Tres versiones rivales de la ética (R. Rovira, Trad.). Madrid: Rialp.

-MacIntyre, A. (2001). Dependent Rational Animals. Why Human Beings Need the Virtues. Chicago: Open Court.

-Nietzsche, F. (1972). La genealogía de la moral (A. Sánchez, Trad.). Madrid: Alianza.

-Rachels, J. (2007). Introducción a la filosofía moral (G. Ortíz Millán, Trad.). México: Fondo de Cultura Económica.

-Rosmini, A. (2010). Principios de la ciencia moral (J. Buganza, Trad.). MéxicoMadrid: Universidad Veracruzana/Plaza y Valdés.

-Scheler, M. (2001). Ética. Nuevo ensayo de fundamentación de un personalismo ético (H. Rodríguez, Trad.). Madrid: Caparrós.

-Zanotti, F. M. (1784). La filosofia morale (Opere di Francesco Maria Cavazzoni Zanotti). (T. IV). Bologna: Stampiera di S. Tommaso D’Aquino. 
Sumario: Introducción; 1. Ética y antropología filosófica; 2. Virtudes morales y

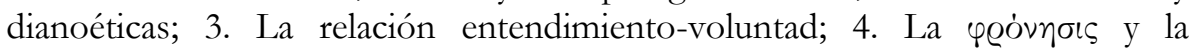
temperantia; 5. Virtudes morales, el fenómeno moral y el bien moral; Conclusiones; Referencias. 